\title{
Ambulant treatment with a digital chest tube for prolonged air leak is safe and effective
}

\author{
Lars Dinjens, Wytze S. de Boer, Jos A. Stigt \\ Department of Pulmonology, Isala Klinieken, Zwolle, The Netherlands \\ Contributions: (I) Conception and design: All authors; (II) Administrative support: L Dinjens, WS de Boer; (III) Provision of study materials or \\ patients: L Dinjens, WS de Boer; (IV) Collection and assembly of data: L Dinjens, WS de Boer; (V) Data analysis and interpretation: L Dinjens, WS \\ de Boer; (VI) Manuscript writing: All authors; (VII) Final approval of manuscript: All authors. \\ Correspondence to: Lars Dinjens. Department of Pulmonology, Isala Klinieken, Dokter van Heesweg 2, Zwolle, 8025 AB, The Netherlands. \\ Email: 1.dinjens@isala.nl.
}

\begin{abstract}
Background: Outpatient or ambulatory treatment for prolonged air leak (PAL) has been reported previously in various studies. Evidence regarding efficiency and safety is nevertheless poor. This report describes the experience of 10 years ambulatory care with a digital chest drain system monitored by specialized nurses in our centre. The aim of the study is to give further insights in the effectiveness and safety of this treatment.

Methods: Retrospective data of 10 years ambulatory care for PAL were examined. One hundred and forty patients with PAL after pneumothorax or pulmonary surgery were included.

Results: A total of 140 patients with PAL were included. Treatment was successful in 112 patients $(80.0 \%)$. Hospital readmission was necessary in 33 patients $(23.6 \%)$ and 28 (20.0\%) of them received additional treatment. Additional treatment consisted of video-assisted thoracoscopic surgery (VATS) in 19 patients (13.6\%), new chest tube placement in 8 patients (5.7\%) and pleurodesis (with talc slurry) in 1 patient $(0.7 \%)$. Minor complications occurred in 10 patients (7.1\%), major complications requiring readmission occurred in 14 patients $(10.0 \%)$.

Conclusions: Ambulatory treatment of PAL with a digital monitoring device resulted in a high success rate with a limited complication rate.
\end{abstract}

Keywords: Chest tubes; pneumothorax; outpatient/ambulatory treatment; prolonged air leak (PAL)

Submitted Jul 21, 2021. Accepted for publication Oct 28, 2021.

doi: $10.21037 /$ jtd-21-1196

View this article at: https://dx.doi.org/10.21037/jtd-21-1196

\section{Introduction}

Outpatient or ambulatory management for uncomplicated spontaneous pneumothorax, chronic malignant pleural effusions and post-operative prolonged air leak (PAL) is reported in various forms, in example treatment with a chest drain or Heimlich valve at home or in a rehab facility (1-4). PAL, defined by the Society of Thoracic Surgeons General Thoracic Surgery Database (STSGTSD) as a parenchymal air leak lasting $>5$ days, is a common clinical problem as a complication of pneumothorax and after lung surgery. PAL complicates $6-18 \%$ of lung resections. PAL is associated with increased cost, a prolonged in hospital length of stay and other complications (5).

In 1975, outpatient treatment for primary spontaneous pneumothorax was first described in the literature (6). In a series of 226 patients with spontaneous pneumothorax, 167 were managed successfully on an outpatient basis by observation $(20 \%)$ or by intercostal tube drainage with a flutter valve $(54 \%)$. Successive reports on outpatient treatment of PAL after lung reduction surgery for emphysema and after (oncologic) pulmonary resection followed afterwards. Cafarotti et al. reported low complication rates as well as fewer re-admissions in the 
outpatient chest drain group, a retrospective review by Royer et al. reported a potential reduction of inpatient hospital days by 305 days without major morbidity or mortality and Rieger et al. suggest that successful outpatient chest tube treatment can be accomplished in select patients $(1,4,7)$.

Several devices have been used in ambulatory management such as the Heimlich valve $(8,9)$, it's modern derivatives the Thoracic Vent and Pleural Vent (10-12), and the Medela Thopaz $^{\odot}$ digital chest drain system $(1,7,13,14)$. Although it seems obvious that outpatient treatment of PAL with reduction of in hospital stay, possible cost reduction and without major comorbidities, is contributory to an optimal treatment. Data on efficacy and safety of outpatient treatment with a digital chest drain system is nevertheless poor.

Ambulatory treatment of PAL requires organization and monitoring. This report describes the 10 years' experience with ambulatory digital chest tube drainage provided by a specialized nursing team called the Chance @ Home program. The aim of this report is to describe the possible benefits and limitations of outpatient treatment in PAL.

We present the following article in accordance with the STROBE reporting checklist (available at https://dx.doi. org/10.21037/jtd-21-1196).

\section{Methods}

\section{Patients}

Patients included in the program had air leak after lung resection (both anatomical and non-anatomical surgery such as wedge resection) or a pneumothorax for at least 5 days or air leak with expected duration $>5$ days and were able to perform daily self-care. Excluded were patient living more than $30 \mathrm{~km}$ from the hospital for safety and logistic reasons. Data on gender, age, indication, in hospital length of stay, chest tube duration (days), initial flow and outcome were collected from the electronic patient record. Outcome was defined as successful if no additional treatment for PAL was necessary. The study was conducted in accordance with the Declaration of Helsinki (as revised in 2013). Approval of the medical ethics committee for analyzing retrospective data was not necessary because of the retrospective design and the anonymity of data. Informed consent for outpatient treatment was obtained from all patients.

\section{Materials}

The treating physician determined the size and type of the chest drain placed, depending on indication and comorbidity. The digital chest drainage system Thopaz ${ }^{\odot}$ from Medela Healthcare Inc. was used in all patients. The Thopaz chest drainage system is a lightweight and compact device with integrated suction and rechargeable battery. Thopaz provides digital real time data and a 24-hour trend of the air leak. The system includes an alarm function in case of irregularities.

\section{Specialized care and procedures}

The 'Chance @ Home' program consisted of a team of specialized nurses to be consulted at discharge from hospital. The nurses visit patients at home on a daily basis for control of vital parameters, drain inspection, and dressing changes. They are available 24/7 for patients in case of emergency, equipment failure, or questions. Patients were readmitted to the emergency department of our hospital after cessation of air leak was established; cessation of air leak was defined as no flow for 12 hours on the Thopaz.

When a chest $X$-ray showed resolution of the pneumothorax, or a stable apical pneumothorax in comparison with the chest X-ray made before discharge, the drain was clamped for 3 hours followed by a control chest X-ray. If the lung did not collapse, the chest tube was removed subsequently and patients were discharged. On average patients spend 4 hours on our emergency department.

\section{Statistical analysis}

Patients characteristics were reported as median or mean and ranges or percentages. Data gathering and all statistical analysis were performed with IBM SPSS software (version 26).

\section{Results}

\section{Patients characteristics}

Between February 2011 and January 2020, 140 patients were included. The patient group consisted of 110 males and 30 females, with a mean age of 51 (range, 16-82) years as seen 
Table 1 Patient characteristics and indications

\begin{tabular}{lc}
\hline Parameters & $\mathrm{N}(\%)$ \\
\hline Gender & $110(21.4)$ \\
Male & $30(78.6)$ \\
Female & \\
Age & $51[19]$ \\
Mean [SD] & \\
Indication & $81(57.9)$ \\
PAL after pulmonary surgery & $59(42.1)$ \\
Pneumothorax
\end{tabular}

$\mathrm{PAL}$, prolonged air leak.

Table 2 Chest tube duration, outcome and complications

\begin{tabular}{|c|c|}
\hline Parameters & $\mathrm{N}(\%)$ \\
\hline \multicolumn{2}{|c|}{ Chest tube duration (days), median [range] } \\
\hline In hospital & $5[1-34]$ \\
\hline Outpatient & $6[1-50]$ \\
\hline \multicolumn{2}{|l|}{ Outcome } \\
\hline Success & $112(80.0)$ \\
\hline Additional intervention & $28(20.0)$ \\
\hline \multicolumn{2}{|l|}{ Complications } \\
\hline Minor & $10(7.1)$ \\
\hline Major & $14(10.0)$ \\
\hline \multicolumn{2}{|l|}{$\begin{array}{l}\text { Minor complications } \\
\text { (not requiring readmission) }\end{array}$} \\
\hline Alarming drain & $7(5.0)$ \\
\hline Subcutaneous emphysema & $2(1.4)$ \\
\hline Pain & $1(0.7)$ \\
\hline \multicolumn{2}{|c|}{ Major complications (requiring readmission) } \\
\hline Relapsed pneumothorax & $4(2.9)$ \\
\hline Trapped lung & $4(2.9)$ \\
\hline Empyema & $2(1.4)$ \\
\hline Drain luxation & $2(1.4)$ \\
\hline Fatigue & $2(1.4)$ \\
\hline
\end{tabular}

in Table 1. Eighty-one patients had PAL after pulmonary surgery $(57.9 \%)$ and 59 patients had PAL after spontaneous pneumothorax (42.1\%) (Table 1).

\section{Chest tube duration}

Chest tube duration was divided in two groups: in hospital chest tube duration followed by ambulatory chest tube duration (Table 2). Median in hospital chest tube duration was 5 (range, 1-34) days. Median outpatient chest tube duration was 6 (range, 1-50) days.

\section{Outcome}

Outpatient treatment of PAL with a chest tube was successful in 112 patients $(80.0 \%)$, no additional treatment was necessary. In 28 patients $(20.0 \%)$ additional treatment was necessary. The initial indication for chest tube placement was PAL after surgery in 6 patients and pneumothorax in 22 patients (Table 2). The patients with PAL underwent surgery for lung cancer [video-assisted thoracoscopic surgery (VATS), robot-assisted thoracoscopic surgery (RATS) or thoracotomy]. Ambulatory treatment was successful in 75 of 81 patients (93\%) in the surgery group, and in 37 of 59 patients (63\%) in the pneumothorax group (Table 2).

\section{Complications}

Complications occurred in 24 patients (17.1\%). Minor complications were alarming drain system, in example due to temporary occlusion by a blood clot, requiring no intervention (7 patients, 5.0\%), subcutaneous emphysema (2 patients, $1.4 \%$ ) and pain (1 patient, $0.7 \%$ ). These complications were solved during the regular visits of the specialized nurses. None of these patients were readmitted to the hospital.

Major complications (requiring readmission to the hospital) were fatigue ( 2 patients, $1.4 \%$ ), relapsed pneumothorax (4 patients, $2.9 \%$ ), trapped lung (4 patients, $2.9 \%)$, empyema (2 patients, $1.4 \%$ ) and drain luxation (2 patients, $1.4 \%)$.

Additional interventions were needed in 28 patients, these consisted of placement of a new chest tube $(n=8)$, pleurodesis $(\mathrm{n}=1)$ and VATS pleurectomy with pleurodesis $(\mathrm{n}=19)$ as shown in Figure 1. Two patients were readmitted to the hospital for observation only. All complications are shown in Table 2.

\section{Discussion}

The ambulatory treatment program with specialized nurses monitoring a digital drainage system as described here 


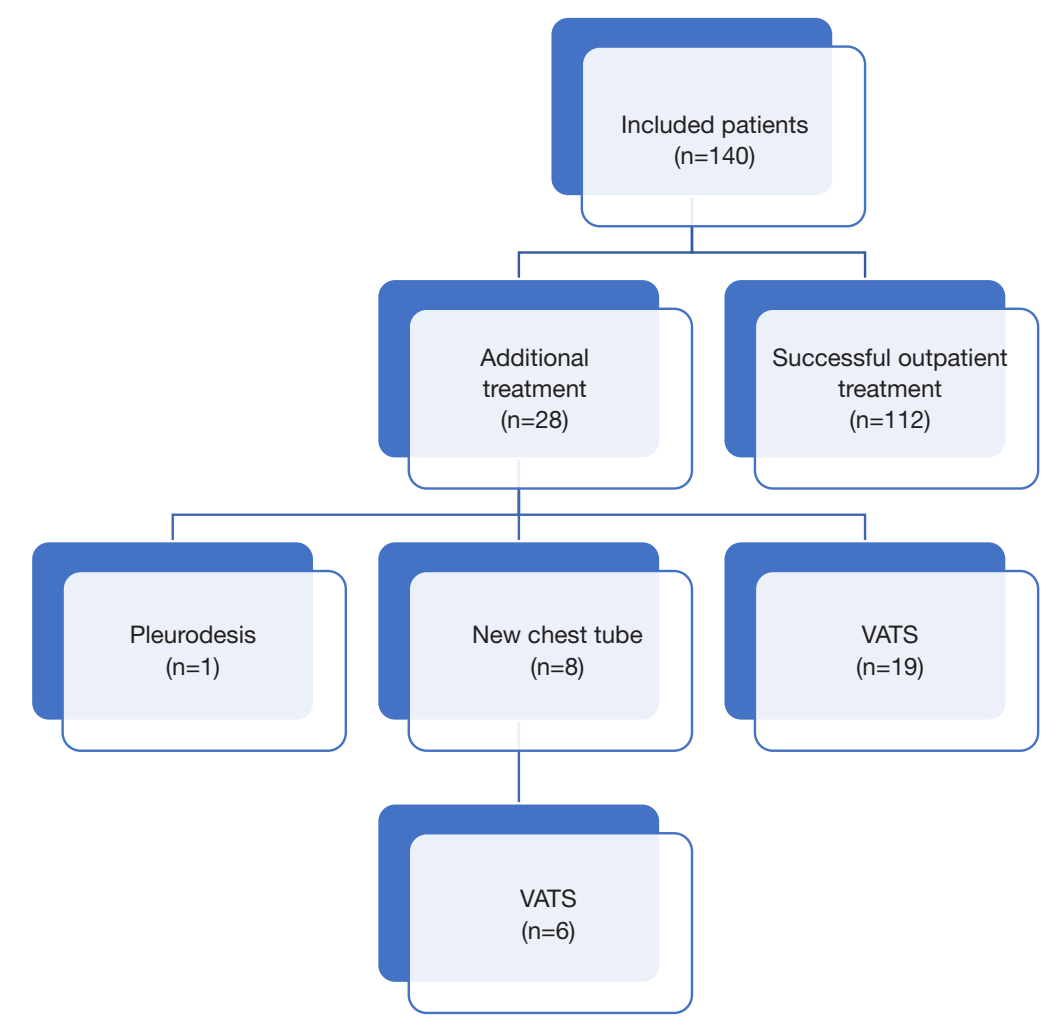

Figure 1 Flow chart. VATS, video-assisted thoracoscopic surgery.

resulted in a successful outpatient treatment of PAL in $80.0 \%$ of patients. In $15.7 \%$ of patients with PAL outpatient treatment failed and subsequent VATS was planned to solve the PAL. These patients were able to wait safely at home for subsequent surgery. A minority of patients had serious adverse events (14 patients, 10.0\%) requiring readmission, comparable to in hospital complication rates described in literature (15). In only $1.4 \%$ of patients the drain dislodged.

It was demonstrated previously that digital monitoring devices for treatment of spontaneous pneumothorax reduced the length of hospital admission significantly with a consequent cost reduction (16). Reports on the postoperative application of digital and ambulatory monitoring devices are conflicting. Some showed a reduced hospital admission time but others were unable to demonstrate differences in hospital admission time and drain days (17-19). Although it is plausible to assume that this program resulted in a reduction in the length of hospital admission, the effect of this program on the length of tube placement is uncertain as patients were not randomized between ambulatory treatment and conventional hospital treatment. For the same reason it is not possible to comment on patient satisfaction although higher satisfaction scores compared with those managed with traditional devices were reported in previous studies (20).

A reduction in costs is suggestive as patients were discharged early with air leaking drains in situ. However cost effectivity was not estimated in this study. A previous study mentioned a cost reduction of almost $\$ 500$ per patient due to shorter in hospital stay (16).

Major limitation of the study is its retrospective design. The program was not compared with conventional clinical treatment leaving the questions about reduced chest tube time, in hospital stay and improved patient's satisfaction, unresolved.

\section{Conclusions}

Ambulatory treatment of PAL with a digital monitoring device resulted in a high success rate with a limited complication rate. 


\section{Acknowledgments}

Funding: None.

\section{Footnote}

Reporting checklist: The authors have completed the STROBE reporting checklist. Available at https://dx.doi. org/10.21037/jtd-21-1196

Data Sharing Statement: Available at https://dx.doi. org/10.21037/jtd-21-1196

Peer Review File: Available at https://dx.doi.org/10.21037/ jtd-21-1196

Conflicts of Interest: All authors have completed the ICMJE uniform disclosure form (available at https://dx.doi. org/10.21037/jtd-21-1196). The authors have no conflicts of interest to declare.

Ethical Statement: The authors are accountable for all aspects of the work in ensuring that questions related to the accuracy or integrity of any part of the work are appropriately investigated and resolved. The study was conducted in accordance with the Declaration of Helsinki (as revised in 2013). Approval of the medical ethics committee for analyzing retrospective data was not necessary because of the retrospective design and the anonymity of data. Informed consent for outpatient treatment was obtained from all patients.

Open Access Statement: This is an Open Access article distributed in accordance with the Creative Commons Attribution-NonCommercial-NoDerivs 4.0 International License (CC BY-NC-ND 4.0), which permits the noncommercial replication and distribution of the article with the strict proviso that no changes or edits are made and the original work is properly cited (including links to both the formal publication through the relevant DOI and the license). See: https://creativecommons.org/licenses/by-nc-nd/4.0/.

\section{References}

1. Cafarotti S, Cusumano G, Giuliani M, et al. Extraanatomical VATS lung resection: the outpatient experience with the aid of a digital chest drain device. Eur Rev Med Pharmacol Sci 2015;19:3850-4.
2. Bintcliffe OJ, Hallifax RJ, Edey A, et al. Spontaneous pneumothorax: time to rethink management? Lancet Respir Med 2015;3:578-88.

3. Schmocker RK, Vanness DJ, Macke RA, et al. Outpatient air leak management after lobectomy: a CMS cost analysis. J Surg Res 2016;203:390-7.

4. Royer AM, Smith JS, Miller A, et al. Safety of Outpatient Chest Tube Management of Air Leaks After Pulmonary Resection. Am Surg 2015;81:760-3.

5. Attaar A, Winger DG, Luketich JD, et al. A clinical prediction model for prolonged air leak after pulmonary resection. J Thorac Cardiovasc Surg 2017;153:690-9.e2.

6. Mercier C, Page A, Verdant A, et al. Outpatient management of intercostal tube drainage in spontaneous pneumothorax. Ann Thorac Surg 1976;22:163-5.

7. Rieger KM, Wroblewski HA, Brooks JA, et al. Postoperative outpatient chest tube management: initial experience with a new portable system. Ann Thorac Surg 2007;84:630-2.

8. McKenna RJ Jr, Fischel RJ, Brenner M, et al. Use of the Heimlich valve to shorten hospital stay after lung reduction surgery for emphysema. Ann Thorac Surg 1996;61:1115-7.

9. Hassani B, Foote J, Borgundvaag B. Outpatient management of primary spontaneous pneumothorax in the emergency department of a community hospital using a small-bore catheter and a Heimlich valve. Acad Emerg Med 2009;16:513-8.

10. Hallifax RJ, McKeown E, Sivakumar P, et al. Ambulatory management of primary spontaneous pneumothorax: an open-label, randomised controlled trial. Lancet 2020;396:39-49.

11. Tsuchiya T, Sano A. Outpatient Treatment of Pneumothorax with a Thoracic Vent: Economic Benefit. Respiration 2015;90:33-9.

12. Kim YP, Haam SJ, Lee S, et al. Effectiveness of Ambulatory Tru-Close Thoracic Vent for the Outpatient Management of Pneumothorax: A Prospective Pilot Study. Korean J Radiol 2017;18:519-25.

13. Cerfolio RJ, Varela G, Brunelli A. Digital and smart chest drainage systems to monitor air leaks: the birth of a new era? Thorac Surg Clin 2010;20:413-20.

14. Varela G, Jiménez MF, Novoa N. Portable chest drainage systems and outpatient chest tube management. Thorac Surg Clin 2010;20:421-6.

15. DeCamp MM, Blackstone EH, Naunheim KS, et al. Patient and surgical factors influencing air leak after lung volume reduction surgery: lessons learned from the 
National Emphysema Treatment Trial. Ann Thorac Surg 2006;82:197-206; discussion 206-7.

16. Jablonski S, Brocki M, Wawrzycki M, et al. Efficacy assessment of the drainage with permanent airflow measurement in the treatment of pneumothorax with air leak. Thorac Cardiovasc Surg 2014;62:509-15.

17. Shoji F, Takamori S, Akamine T, et al. Clinical Evaluation and Outcomes of Digital Chest Drainage after Lung Resection. Ann Thorac Cardiovasc Surg 2016;22:354-8.

18. Gilbert S, McGuire AL, Maghera S, et al. Randomized trial of digital versus analog pleural drainage in patients

Cite this article as: Dinjens L, de Boer WS, Stigt JA. Ambulant treatment with a digital chest tube for prolonged air leak is safe and effective. J Thorac Dis 2021;13(12):6810-6815. doi: $10.21037 /$ jtd-21-1196 with or without a pulmonary air leak after lung resection. J Thorac Cardiovasc Surg 2015;150:1243-9.

19. Lijkendijk M, Licht PB, Neckelmann K. Electronic versus traditional chest tube drainage following lobectomy: a randomized trial. Eur J Cardiothorac Surg 2015;48:893-8; discussion 898.

20. Brunelli A, Cassivi SD, Salati M, et al. Digital measurements of air leak flow and intrapleural pressures in the immediate postoperative period predict risk of prolonged air leak after pulmonary lobectomy. Eur J Cardiothorac Surg 2011;39:584-8. 